\title{
Effects of Life style factors on the symptoms of gastro esophageal reflux disease: A cross sectional study in a Pakistani population
}

\author{
Shahid Ahmed ${ }^{1}$, Sajjad Jamil ${ }^{2}$, \\ Hafeezullah Shaikh ${ }^{3}$, Maryam Abbasi ${ }^{4}$
}

\begin{abstract}
Background \& Objective: Gastro esophageal reflux disease (GERD) broadly includes the whole spectrum of reflux disease symptoms like heartburn or acid regurgitation to endoscopic, reflux esophagitis or Barrett's esophagus. Our aim therefore was to study the association between Gastroesophageal reflux disease symptoms and various lifestyle factors.

Methods: A descriptive cross-sectional study was carried out in the outpatient department of Darul Sehat Hospital, Zubaida Medical Center and Liaquat National Hospital \& Medical College, Karachi, Pakistan from January 2018 to October 2018. The selected candidates were asked to fill a validated GERD questionnaire and they were also asked about their lifestyle factors. Odds ratio and their $95 \%$ confidence interval were estimated using binary logistic regression with GERD symptoms as the study outcome.

Results: A total of 2000 respondents completed the questionnaire. $69.3 \%$ gastroesophageal reflux disease cases were found in participants above 35 years of age while $56.9 \%$ subjects were male. The most common lifestyle factors associated with GERD were less exercise time (90.9\%) (OR, 6.47; 95\% Cl, 4.91-8.53), 78.3\% participants had habit of eating midnight snacks (OR, 5.08; $95 \% \mathrm{Cl}, 4.03-6.40), 87.3 \%$ participants reported less interval between dinner and sleep $(\mathrm{OR}, 6.98 ; 95 \% \mathrm{Cl}, 5.36-9.08)$. The most important factor relieving GERD symptoms was raising the head of bed during sleep $(79.4 \%)$ while $43.3 \%$ subjects with the habit of post dinner walk reported fewer symptoms of GERD.

Conclusion: Lifestyle factors particularly less physical activity, late evening meals, inadequate sleep, smoking and post dinner lying were found to be associated with GERD symptoms.
\end{abstract}

KEYWORDS: Lifestyle, Gastroesophageal reflux, Smoking, Sleep deprivation, Exercise.

doi: https://doi.org/10.12669/pjms.36.2.1371

How to cite this:

Ahmed S, Jamil S, Shaikh H, Abbasi M. Effects of Life style factors on the symptoms of gastro esophageal reflux disease: A cross sectional study in a Pakistani population. Pak J Med Sci. 2020;36(2):115-120. doi: https://doi.org/10.12669/pjms.36.2.1371

This is an Open Access article distributed under the terms of the Creative Commons Attribution License (http://creativecommons.org/licenses/by/3.0), which permits unrestricted use, distribution, and reproduction in any medium, provided the original work is properly cited.

\section{INTRODUCTION}

Gastro esophageal reflux disease (GERD) broadly includes the whole spectrum of reflux disease from intermittent symptoms like heartburn or acid regurgitation to endoscopic, reflux esophagitis or

Correspondence:

Dr. Hafeezullah Shaikh,

National Institute of Liver and GI Diseases,

Dow University of Health Sciences,

\& Zubaida Medical Center, Karachi, Pakistan.

E-mail: hafeezmurad@gmail.com

* Received for Publication:

July 18, 2019

* Revision Received:

* Revision Accepted:

November 16, 2019
Barrett's esophagus. ${ }^{1}$ About $10-20 \%$ of population in western countries report weekly symptoms of GERD. ${ }^{2}$ A study has shown the prevalence of GERD to be $18.1-27.8 \%$ in North America, $8.8-25.9 \%$ in Europe, $2.5-7.8 \%$ in East Asia, $8.7-33.1 \%$ in the Middle East, $11.6 \%$ in Australia and $23.0 \%$ in South America. ${ }^{3}$ In Pakistan it is more common in urban population. ${ }^{4}$ GERD is characterized by reflux of acid, bile, pepsin and pancreatic enzymes due to transient lower esophageal sphincter relaxations and other lower esophageal sphincter pressure abnormalities. This leads to mucosal injury. Other factors contributing to the pathophysiology of GERD include hiatal hernia, impaired esophageal clearance, delayed gastric 
emptying and impaired mucosal defensive factors. ${ }^{5}$ GERD has a wide range of clinical manifestations from symptoms like chest pain, hoarseness of voice, sore throat, dry cough, burning sensation in chest, food regurgitation to alarming symptoms like dysphagia, odynophagia, anemia and weight loss.

These symptoms can lead to possible complications, including erosive esophagitis, ulcerations, strictures and gastrointestinal bleeding if remain untreated. ${ }^{6}$ According to the American College of Gastroenterology (ACG) the commonly applied diagnostic tools for GERD are upper GI endoscopy, esophageal manometry and ambulatory 24 hour $\mathrm{pH}$ monitoring. As suggested by ACG lifestyle measures for GERD are elevation of the head of bed, decrease fat intake, cessation of smoking and avoiding recumbence for three hours post prandial. ${ }^{7}$ Most of the literature showing the association between GERD and lifestyle factors is from the western world. In South Asia limited relevant data are available checking association of GERD with only two or three lifestyle factors. To the best of authors' knowledge, this study is the first of its kind evaluating in detail the association of all the major lifestyle factors with GERD in Pakistan.

\section{METHODS}

A descriptive cross-sectional study was carried out in outpatient department of Darul Sehat Hospital, Zubaida Medical Center and Liaquat National Hospital \& Medical College, Karachi, Pakistan from January 2018 to October 2018. A total of 2000 individuals, aged 18 years or above, were included in the study by means of convenient sampling. Participants with history of comorbid like diabetes mellitus, hypertension, acid peptic disease chronic liver disease or chronic use of NSAIDS were excluded. The calculated sample size was 1750 using $24 \%$ GERD prevalence, ${ }^{4}$ 95\% confidence interval, $5 \%$ precision and $80 \%$ power which was inflated by $10-12 \%$ to account for non-responders. A pilot feasibility study was conducted by administering the questionnaire to 100 participants. Pilot study was conducted both in Urdu and English languages. After obtaining approval from ethical review committee (IRB-010/LCMD/13, Dated 09 February 2017) a validated questionnaire was administered by the volunteers, under direct supervision of the principal investigator. The questionnaire was administered after obtaining written consent of the participants. It comprised of three sections, demographics, "Ritcher Acid Scale "questionnaire for the screening of GERD ${ }^{4}$ and lifestyle factors.
A cutoff point of two or greater was selected to confirm the presence of GERD. The participants were divided into two equal groups (GERD positive and GERD negative) using non-probability purposive sampling. Administered questionnaire was adapted from previously published studies. ${ }^{7,8}$ Each participant was classified as underweight, normal, over weight and obese according to the cutoff value of BMI used in a previous study conducted on an Asian population. ${ }^{9}$ Age of the study participants was divided into two groups to observe the association of GERD symptoms with increasing age i.e. $\leq 35$ years and $>35$ years.

Data were entered and analyzed using statistical package for social sciences (SPSS) version 16.0 Frequencies and percentages were calculated for baseline characteristics like gender, age group, ethnicity and body mass index. Independent sample ttest was used to compare the means of two groups whereas Pearson chi square test was used to determine the association of GERD with baseline parameters and also with life style characteristics. Binary logistic analysis was used to develop a risk assessment model for the study outcome. All p-value less than 0.05 were considered statistically significant.

\section{RESULTS}

Out of a total of 2000 individuals included in the study $n=842$ were males and $n=1158$ were females. Of male and female individuals, $\mathrm{n}=569(67.7 \%)$ and $\mathrm{n}=431(37.3 \%)$ had GERD respectively. GERD cases were found to be more common in individuals $(77.96 \%)$ aged more than 35 years. The highest prevalence of GERD found within Pashto ethnicity $(28.9 \%)$. All socio-demographic characteristics studied were significantly associated with GERD $(\mathrm{p}<0.05)$ (Table-I).

Forty two percent $(42.2 \%)$ of the participants reported increased weight in the adulthood, 90.9\% exercised less than 30 minutes a day, $78.3 \%$ had habit of taking midnight snacks, $77.5 \%$ said that they had inadequate sleep, $69.4 \%$ skipped the breakfast on frequent basis, $87.3 \%$ said that they eat dinner within two hours of going to sleep, $42.6 \%$ had habit of smoking, $60.6 \%$ were smoking for more than five years, $44.3 \%$ reported to smoke more than ten cigarettes per day, $5.1 \%$ reported drinking alcohol, $13 \%$ had habit of chewing pan, $96.5 \%$ drank less than eight cups of tea per day, $79.4 \%$ accepted that raising head of bed during sleep relieves heartburn, $21.4 \%$ said that they increase duration between eating and sleeping to relieve heartburn, $20.8 \%$ did walking after dinner, $69.5 \%$ used to lie down or 
Table-I: Association of GERD with Baseline Characteristics of studied Samples $(n=2000)$.

\begin{tabular}{|c|c|c|c|c|c|c|}
\hline \multicolumn{2}{|c|}{ Baseline Characteristics } & \multicolumn{4}{|c|}{ GERD } & \multirow[t]{3}{*}{ p-value } \\
\hline & & \multicolumn{2}{|c|}{ Negative $(n=1000)$} & \multicolumn{2}{|c|}{ Positive $(n=1000)$} & \\
\hline & & $N$ & $\%$ & $N$ & $\%$ & \\
\hline \multirow[t]{2}{*}{ Gender } & Male $(\mathrm{n}=842)$ & 272 & 32.34 & 569 & 67.7 & \multirow[t]{2}{*}{$<0.01^{*}$} \\
\hline & Female $(n=1158)$ & 727 & 62.7 & 431 & 37.3 & \\
\hline Age & Mean, SD & 30.0 & 10.47 & 44.73 & 13.92 & $<0.01^{* *}$ \\
\hline \multirow[t]{2}{*}{ Age group } & $\leq 35$ years $(n=1111)$ & 804 & 72.4 & 307 & 27.6 & \multirow[t]{2}{*}{$<0.01^{*}$} \\
\hline & $>35$ Years $(\mathrm{n}=889)$ & 196 & 22.04 & 693 & 77.96 & \\
\hline \multirow[t]{5}{*}{ Ethnicity } & Punjabi & 181 & 18.1 & 118 & 11.8 & \multirow[t]{5}{*}{$<0.01^{*}$} \\
\hline & Sindhi & 160 & 16.0 & 171 & 17.1 & \\
\hline & Pashto & 181 & 18.1 & 289 & 28.9 & \\
\hline & Baluchi & 115 & 11.5 & 206 & 20.6 & \\
\hline & Urdu & 363 & 36.3 & 216 & 21.6 & \\
\hline BMI & Mean, SD & 24.54 & 5.20 & 26.42 & 5.13 & $<0.01^{* *}$ \\
\hline \multirow[t]{4}{*}{$\mathrm{BMI}(\mathrm{kg} / \mathrm{m} 2)$} & Normal (18.5-22.9) & 322 & 32.2 & 184 & 18.4 & \multirow[t]{4}{*}{$<0.01^{*}$} \\
\hline & Underweight $(<18.5)$ & 65 & 6.5 & 22 & 2.2 & \\
\hline & Overweight (23-26.9) & 320 & 32.0 & 431 & 43.1 & \\
\hline & Obese $(\geq 27)$ & 293 & 29.3 & 363 & 36.3 & \\
\hline
\end{tabular}

${ }^{*} \mathrm{p}<0.05$ was considered significant using Pearson chi square test

**Mean differences considered significant using Independent Sample t-test.

walk whereas $30.5 \%$ used to sit or be in recumbent position for post dinner physical activity, $11.2 \%$ said that they did fifteen or more minutes exercise daily. All of these lifestyle factors were significantly associated with GERD $(\mathrm{p}<0.05)$ (Table-II). Binary logistic regression analysis further showed that

Table-II: Association of GERD with life style behaviors of studied samples $(n=2000)$.

\begin{tabular}{|c|c|c|c|c|c|c|}
\hline \multirow[t]{2}{*}{ Life Style Behaviors } & & \multicolumn{2}{|c|}{$\begin{array}{c}\text { GERD Negative } \\
(n=1000)\end{array}$} & \multicolumn{2}{|c|}{$\begin{array}{c}\text { GERD Positive } \\
(n=1000)\end{array}$} & \multirow[t]{2}{*}{ p-value } \\
\hline & & $N$ & $\%$ & $N$ & $\%$ & \\
\hline Body weight increased in adulthood & Yes & 366 & 36.6 & 422 & 42.2 & $<0.01^{*}$ \\
\hline Exercise time less than 30 minutes & Yes & 525 & 52.5 & 909 & 90.9 & $<0.01^{*}$ \\
\hline Habit of midnight snacks & Yes & 372 & 37.2 & 783 & 78.3 & $<0.01^{*}$ \\
\hline Feeling of inadequate sleep & Yes & 448 & 44.8 & 775 & 77.5 & $<0.01^{*}$ \\
\hline Frequent skipping of breakfast & Yes & 441 & 44.1 & 694 & 69.4 & $<0.01^{*}$ \\
\hline Dinner within two hours before going to sleep & Yes & 504 & 50.4 & 873 & 87.3 & $<0.01^{*}$ \\
\hline Habit of smoking & Yes & 86 & 8.6 & 426 & 42.6 & $<0.01^{*}$ \\
\hline \multirow[t]{2}{*}{ Smoking since how many years } & $\leq 5$ years & 62 & 72.1 & 169 & 39.4 & $<0.01^{*}$ \\
\hline & $>5$ years & 24 & 27.9 & 260 & 60.6 & \\
\hline \multirow[t]{2}{*}{ Number of cigarettes daily } & $\leq 10$ & 77 & 89.6 & 239 & 55.7 & $<0.01^{*}$ \\
\hline & $>10$ & 9 & 10.5 & 190 & 44.3 & \\
\hline Habit of alcohol drinking & Yes & 9 & 0.9 & 51 & 5.1 & $<0.01^{*}$ \\
\hline $\begin{array}{l}\text { On how many occasions you consumed alcohol } \\
\text { in last } 2 \text { weeks }\end{array}$ & $1-4$ times & 9 & 0.9 & 51 & 5.1 & $<0.01^{*}$ \\
\hline Habit of chewing pan & Yes & 140 & 14 & 130 & 13 & 0.531 \\
\hline \multirow[t]{2}{*}{ Cups of tea daily } & Never & 279 & 27.9 & 35 & 3.5 & $<0.01^{*}$ \\
\hline & $\leq 8$ & 721 & 72.1 & 965 & 96.5 & \\
\hline Raising head of bed during sleep relieve heartburn & Yes & 197 & 19.7 & 794 & 79.4 & $<0.01^{*}$ \\
\hline $\begin{array}{l}\text { Increasing duration between eating and } \\
\text { sleeping relieve heartburn }\end{array}$ & Yes & 291 & 29.1 & 214 & 21.4 & $<0.01^{*}$ \\
\hline Walking after dinner relieve heartburn & Yes & 567 & 56.7 & 208 & 20.8 & $<0.01^{*}$ \\
\hline \multirow[t]{2}{*}{ Post dinner physical activity } & Lying or Walking & 563 & 56.3 & 695 & 69.5 & $<0.01^{*}$ \\
\hline & Sitting or Recumbent & it 437 & 43.7 & 305 & 30.5 & \\
\hline \multirow[t]{2}{*}{ How long exercise daily } & Never & 354 & 35.4 & 888 & 88.8 & $<0.01^{*}$ \\
\hline & 15 or more minutes & 646 & 64.6 & 112 & 11.2 & \\
\hline
\end{tabular}

${ }^{*} \mathrm{p}<0.05$ was considered significant using Pearson chi square test. 
Table-III: Odds Ratio Estimation of GERD with Life Style Characteristics using Binary Logistic Regression.

\begin{tabular}{|c|c|c|c|c|c|}
\hline \multirow[t]{2}{*}{ Life Style Characteristics } & & \multicolumn{2}{|c|}{ Univariate Analysis } & \multicolumn{2}{|c|}{ Multivariate Analysis } \\
\hline & & $\begin{array}{l}\text { Odds } \\
\text { Ratio }\end{array}$ & $\begin{array}{l}95 \% \text { Confidence } \\
\text { interval }\end{array}$ & $\begin{array}{l}\text { Odds } \\
\text { Ratio }\end{array}$ & $\begin{array}{l}95 \% \text { Confidence } \\
\text { interval }\end{array}$ \\
\hline Body weight increased in adulthood & Yes & $1.26^{*}$ & $1.05,1.51$ & 1.19 & $0.96,1.49$ \\
\hline Exercise time less than 30 minutes & Yes & $9.03 *$ & $7.04,11.58$ & $6.47^{*}$ & $4.91,8.53$ \\
\hline Habit of midnight snacks & Yes & $6.09 *$ & $4.99,7.42$ & $5.08^{*}$ & $4.03,6.40$ \\
\hline Feeling of inadequate sleep & Yes & $4.24^{*}$ & $3.49,5.15$ & $3.22 *$ & $2.57,4.03$ \\
\hline Frequent skipping of breakfast & Yes & $2.85^{*}$ & $2.39,3.54$ & $2.70^{*}$ & $2.17,3.35$ \\
\hline Dinner within two hours before going to sleep & Yes & 6.76 & $5.40,8.46$ & $6.98^{*}$ & $5.36,9.08$ \\
\hline Habit of smoking & Yes & 7.88 & $6.11,10.17$ & $6.25^{*}$ & $4.40,8.91$ \\
\hline Habit of alcohol drinking & Yes & $5.91^{*}$ & $2.89,12.08$ & 1.68 & $0.76,3.68$ \\
\hline Raising head of bed during sleep relieve heartburn & Yes & $15.71^{*}$ & $12.62,19.54$ & $11.95^{*}$ & $9.31,15.32$ \\
\hline $\begin{array}{l}\text { Increasing duration between eating and } \\
\text { sleeping relieve heartburn }\end{array}$ & Yes & $0.66^{*}$ & $0.54,0.81$ & 0.83 & $0.65,1.06$ \\
\hline Walking after dinner relieve heartburn & No & $4.98^{*}$ & $4.09,6.07$ & $3.92 *$ & $3.12,4.93$ \\
\hline \multirow[t]{3}{*}{ Post dinner physical activity } & Lying & $3.61^{*}$ & $2.09,6.23$ & $2.24^{*}$ & $1.19,4.20$ \\
\hline & Walking & $0.36^{*}$ & $0.21,0.62$ & $0.25^{*}$ & $0.13,0.47$ \\
\hline & Sitting & 0.6 & $0.35,1.05$ & $0.45^{*}$ & $0.24,0.84$ \\
\hline \multirow[t]{3}{*}{ How long exercise daily } & 15 minutes & $0.11^{*}$ & $0.08,0.15$ & $0.14^{*}$ & $0.10,0.20$ \\
\hline & 30 minutes & $0.05^{*}$ & $0.03,0.08$ & $0.04^{*}$ & $0.02,0.07$ \\
\hline & >30 minutes & $0.02 *$ & $0.01,0.03$ & $0.02 *$ & $0.01,0.03$ \\
\hline
\end{tabular}

*p<0.05 was considered significant.

a Model were adjusted for Age, Gender and BMI.

males had 3.52 times higher risk of GERD as compared to females while older age and increased BMI also increased the risk of GERD.

Results for assessing association of various lifestyle factors with GERD further showed that individuals with increased body weight in adulthood, exercising less than 30 minutes a day, habit of taking midnight snacks, having inadequate sleep, skipping breakfast, eating dinner within two hours of going to sleep and habit of smoking were at high risk of GERD.

Furthermore, the multivariate model adjusted for age, gender and BMI of the participants showed that odds of life style risk factors to be associated with GERD decreased as compared to the un-adjusted model, and body weight increase in adulthood became an insignificant risk in the multivariable model (Table-III).

Moreover, in the univariate model people who increased duration of sleep time between eating and sleeping were 0.66 times less likely to have GERD (OR, 0.66; 95\% CI, 0.54-0.81). Walking as post dinner activity also decreased the odds of having GERD (OR, 0.36; 95\% CI, 0.21-0.62). Increased time of exercise on daily basis also decreased the odds of having GERD i.e. for 15 minutes (OR, 0.11; 95\% $\mathrm{CI}, 0.08-0.15)$, for 30 minutes (OR, 0.05; 95\% CI, $0.03-0.08$ ) and for $>30$ minutes (OR, $0.02 ; 95 \% \mathrm{CI}$, 0.01-0.03) (Table-III).
The study results further showed that $60 \%$ cases of GERD reported for the uncomfortable feeling behind the breast bone, $62.4 \%$ felt burning sensation in the back of throat, $9.6 \%$ reported for a bitter acid taste in mouth, $95.3 \%$ cases experienced problem after meal, $47.5 \%$ said antacid only provide temporary relief and $44.8 \%$ cases of GERD said they taking prescription medication for heart burn still having symptoms (Table-IV).

\section{DISCUSSION}

GERD is closely linked to lifestyle factors that facilitate acid reflux by sphincter relaxation or stimulating acid secretions. Most of the data comparing GERD and lifestyle factors are from the western countries. This study focused on the impact of lifestyle factors on GERD in Pakistan. In our study the target population was patients visiting the outpatient department of a tertiary care hospital of Karachi. The study population belonged to diverse ethnicities from rural and urban areas of Pakistan. A study performed in India reported higher prevalence of GERD in urban population with odds ratio of $1.8^{10}$ though contrary to our findings where the highest prevalence of GERD was found in Pashto speaking individuals $(28.9 \%)$ who were mostly from the rural areas of Pakistan. 
Table-IV: Ritcher acid scale of both GERD and Control Group.

\begin{tabular}{|c|c|c|c|c|c|}
\hline \multirow[t]{3}{*}{ Scale } & & \multicolumn{4}{|c|}{ GERD } \\
\hline & & \multicolumn{2}{|c|}{ Negative } & \multicolumn{2}{|c|}{ Positive } \\
\hline & & $n$ & $\%$ & $n$ & $\%$ \\
\hline \multirow{2}{*}{$\begin{array}{l}\text { An uncomfortable feeling behind the breast bone that seems } \\
\text { to be moving upward from the stomach. }\end{array}$} & No & 821 & 82.1 & 400 & 40.0 \\
\hline & Yes & 179 & 17.9 & 599 & 60.0 \\
\hline \multirow[t]{2}{*}{ A burning sensation in the back of your throat. } & No & 851 & 85.1 & 376 & 37.6 \\
\hline & Yes & 149 & 14.9 & 624 & 62.4 \\
\hline \multirow[t]{2}{*}{ A bitter acid taste in your mouth. } & No & 889 & 88.9 & 904 & 90.4 \\
\hline & Yes & 111 & 11.1 & 96 & 9.6 \\
\hline \multirow[t]{2}{*}{ Do you experience these problems after meal } & No & 999 & 99.9 & 47 & 4.7 \\
\hline & Yes & 1 & 0.1 & 953 & 95.3 \\
\hline \multirow[t]{2}{*}{ Heartburn two times per week } & No & 1000 & 100.0 & 178 & 17.8 \\
\hline & Yes & 0 & 0.0 & 822 & 82.2 \\
\hline \multirow[t]{2}{*}{ Antacids only provide temporary relief } & No & 1000 & 100.0 & 525 & 52.5 \\
\hline & Yes & 0 & 0.0 & 475 & 47.5 \\
\hline \multirow{2}{*}{$\begin{array}{l}\text { Taking prescription medication for heartburn } \\
\text { but still having symptoms }\end{array}$} & No & 1000 & 100.0 & 552 & 55.2 \\
\hline & Yes & 0 & 0.0 & 448 & 44.8 \\
\hline
\end{tabular}

A higher prevalence of GERD was found with increasing age, 69.5\% patients who reported GERD symptoms were above 35 years of age (OR, 9.26), confirming the findings of a study conducted in Albania demonstrating a higher prevalence of GERD among older participants (OR 1.85). ${ }^{11}$ This has been supported by other studies highlighting the likelihood of developing GERD in old age. ${ }^{12,13}$ On the other hand few studies failed to show any association of GERD with age $\mathrm{e}^{14,15}$ and the idea of developing GERD with increasing age remains controversial.

Higher BMI was found as a risk factor for GERD in the studies from North America ${ }^{16}$ but a study from Bangladesh found no association between GERD and BMI. ${ }^{17}$ In our study though, a significant difference was found in the prevalence of GERD with increasing BMI with odds ratio of 2.35 and 2.16 in overweight and obese participants respectively.

In our study, prevalence estimates of GERD were higher among men than women with odds ratio of 3.52. This can be comparable to the findings of another study conducted in Pakistan. ${ }^{4}$

Recumbence and lying down after meals are known risk factors of GERD. ${ }^{18}$ The protective effect of normal physical activity in GERD has been highlighted in many studies. ${ }^{19}$ It has been demonstrated in our study that GERD symptoms are more prevalent in physically inactive participants with exercise time of less than 30 minutes (OR, 6.47). The odds ratio of post dinner lying was significant (OR, 2.24) when compared with recumbence in our study.

It is a common belief that some dietary habits would aggravate GERD such as dinner within two hours before going to sleep or taking a midnight snack. In our study the odds ratio of developing GERD in participants taking midnight snacks was 5.08 while for dinner within two hours before going to sleep was 6.98. This association has been previously proved in a study conducted in Korea. ${ }^{20}$

Another study showed that individuals with poor quality sleep had more symptoms of GERD. ${ }^{21}$ The exact mechanism for why a subject sleeps fewer hours remain unknown, but gastric motor function is known to be active during sleep. ${ }^{22}$ Thus inadequate sleep could disturb this motor function and may induce GERD. In the present study, 77.5\% individuals with GERD reported inadequate sleep (OR, 3.22).

People who stay empty stomach are prone to develop GERD. This was also shown in our study with $69.4 \%$ of GERD positive subjects reporting frequent skipping of breakfast (OR, 2.70). Smoking has often been cited as a risk factor for GERD. Although the findings on this matter are inconsistent, several studies showed direct relationship of GERD with smoking. ${ }^{23,24}$ In the current study GERD was found to be more common in individuals who smoked with odds ratio of 6.25 . In the current study, $79.4 \%$ participants reported improvement in the severity of GERD with elevating the head of the bed during sleep.

Limitations of the study: The limitations of the study include self-reported diagnosis of GERD based on history and not on endoscopic findings. Furthermore, recall bias might have affected the study results because questionnaire required the 
participants to recall previous events in the past few weeks. Moreover, it is also acknowledged that the use of convenience sampling technique due to resource constraints may have limited the generalizability of the study findings.

\section{CONCLUSION}

The study results confirm that lifestyle factors have a significant association with GERD symptoms. The most common socio-demographic risk factors identified for developing GERD were older age, higher BMI, male gender and rural population. Moreover, the lifestyle factors that may lead to GERD were lack of exercise, taking midnight snacks, skipping breakfast, smoking and lack of sleep. Further interventional studies are needed to see the impact of lifestyle changes in controlling the symptoms of GERD. Effective measures should be taken to spread awareness about lifestyle modifications.

In this study we used non-invasive means of diagnosing GERD which is primarily used in such cases. We can easily use "Ritcher Acid Scale" for identifying individuals at high risk for developing GERD and then they should be counseled about all these lifestyle measures pointed out in our study for preventing the disease.

Conflict of Interest: All authors have no conflict of interest to declare.

Funding Disclosure: No funding received for this specific study project.

\section{REFERENCES}

1. Vakil N, van Zanten S, Kahrilas P, Dent J, Jones R. The Montreal Definition and Classification of Gastroesophageal Reflux Disease: A Global Evidence-Based Consensus. Am J Gastroenterol 2006;101(8):1900-1920. doi: 10.1111/j.1572-0241.2006.00630.x

2. Dent J, El-Serag HB, Wallander M, Johansson S. Epidemiology of gastro-oesophageal reflux disease: A systematic review. Gut. 2005;54(5):710-717. doi: 10.1136/gut.2004.051821

3. El-Serag HB, Sweet S, Winchester CC, Dent J. Update on the epidemiology of gastro-oesophageal reflux disease: A systematic review. Gut. 2014;63(6):871-880. doi: 10.1136/gutjnl-2012-304269

4. Jafri N, Jafri W, Yakoob J, Islam M, Manzoor S, Jalil A, et al. Perception of gastroesophageal reflux disease in urban population in Pakistan J Coll Physicians Surg Pak. 2005;15(9):532-534. doi: 09.2005/ JCPSP.532534

5. De Giorgi F, Palmiero M, Esposito I, Mosca F, Cuomo R Pathophysiology of gastro-oesophageal reflux disease. Acta Otorhinolaryngologica Italica. 2006;26(5):241-246.

6. Pisegna J, Holtmann G, Howden CW, Katelaris $\mathrm{PH}$, Sharma P, Spechler S, et al. Oesophageal complications and consequences of persistent gastro-oesophageal reflux disease. Aliment Pharmacol Ther. 2004;20:47-56. doi: 10.1111/j.1365-2036.2004.02240.x

7. DeVault KR, Castell DO. Updated guidelines for the diagnosis and treatment of gastroesophageal reflux disease. Am J Gastroenterol. 2005;100(1):190-200. doi: 10.1111/j.1572-0241.2005.41217.x

8. Yamamichi N, Mochizuki S, Asada-Hirayama I, Mikami-Matsuda $\mathrm{R}$, Shimamoto T, Konno-Shimizu M, et al. Lifestyle factors affecting gastroesophageal reflux disease symptoms: A cross-sectional study of healthy 19864 adults using FSSG scores. BMC Med. 2012;10-45. doi: 10.1186/1741-7015-10-45
9. Jafar TH, Chaturvedi N, Pappas G. Prevalence of overweight and obesity and their association with hypertension and diabetes mellitus in an Indo-Asian population. CMAJ. 2006;175(9):1071-1077. doi: 10.1503/cmaj.060464

10. Wang HY, Leena KB, Plymoth A, Hergens MP, Yin L, Shenoy KT, et al Prevalence of gastro-esophageal reflux disease and its risk factors in a community-based population in southern India. BMC Gastroenterol. 2016;16(1):36. doi: 10.1186/s12876-016-0452-1

11. Cela L, Kraja B, Hoti K, Toci E, Muja H, Roshi E, et al. Lifestyle characteristics and gastroesophageal reflux disease: A populationbased study in Albania. Gastroenterol Res Pract. 2013 Article ID 936792. doi: $10.1155 / 2013 / 936792$

12. Okimoto $\mathrm{E}$, Ishimura $\mathrm{N}$, Morito $\mathrm{Y}$, Mikami H, Shimura S, Uno $\mathrm{G}$ et al. Prevalence of gastroesophageal reflux disease in children, adults, and elderly in the same community. J Gastroenterol Hepatol. 2015;30(7):1140-1146. doi: 10.1111/jgh.12899.

13. Achem SR, DeVault KR. Gastroesophageal reflux disease and the elderly. Gastroenterol Clin North Am. 2014;43(1):147-160. doi 10.1016/j.gtc.2013.11.004

14. Kennedy $\mathrm{T}$, Jones $\mathrm{R}$. The prevalence of gastro-oesophageal reflux symptoms in a UK population and the consultation behaviour of patients with these symptoms. Aliment Pharmacol Ther. 2000;14(12):1589-1594.

15. Haque M, Wyeth JW, Stace NH, Talley NJ, Green R. Prevalence, severity and associated features of gastro-oesophageal reflux \& dyspepsia: A population-based study. N Z Med J. 2000;113(1110):178-181.

16. Chang P, Friedenberg F. Obesity and GERD. Gastroenterol Clin North Am. 2014;43(1):161-173. doi: 10.1016/j.gtc.2013.11.009

17. Shaha M, Perveen I, Alamgir MJ, Masud MH, Rahman MH Prevalence and risk factors for gastro-esophageal reflux disease in the North-Eastern part of Bangladesh. Bangladesh Med Res Counc Bull 2012;38(3):108-113. doi: 10.3329/bmrcb.v38i3.14338

18. Karim S, Jafri W, Faryal A, Majid S, Salih M, Jafri F, et al. Regular post dinner walk; can be a useful lifestyle modification for gastroesophageal reflux. J Pak Med Assoc. 2011;61(6):526-530.

19. Nilsson M, Johnsen R, Ye W, Hveem K, Lagergren J. Lifestyle related risk factors in the aetiology of gastro-oesophageal reflux. Gut. 2004;53(12):1730-1735. doi: 10.1136/gut.2004.043265

20. Choi YJ, Ha EK, Jeong SJ. Dietary habits and gastroesophageal reflux disease in preschool children Korean J Pediatr. 2016;59(7):303-307. doi: 10.3345/kjp.2016.59.7.303

21. Dickman R, Green C, Fass SS, Quan SF, Dekel R, Risner-Adler S, et al. Relationships between sleep quality and $\mathrm{pH}$ monitoring findings in persons with gastroesophageal reflux disease. J Clin Sleep Med. 2007;3(05):505-513.

22. Orr WC, Chen CL. Sleep and the gastrointestinal tract. Neurol Clin. 2005;23(4):1007-1024. doi: 10.1016/j.ncl.2005.05.004

23. Watanabe $Y$, Fujiwara $Y$, Shiba M, Watanabe T, Tominaga K, Oshitan $\mathrm{N}$, et al. Cigarette smoking and alcohol consumption associated with gastro-oesophageal reflux disease in Japanese men. Scand J Gastroenterol. 2003;38(8):807-811.

24. Rabiee B, Motamed N, Hosseini V, Hemasi GR, Maadi M, Zamani F. Gastro esophageal reflux disease (GERD) prevalence and related risk factors in north of Iran. Esophagus. 2016;13(4):330-336.

Author Contribution: SA, HS: Conceived, designed and did statistical analysis \& editing of manuscript. SJ, MA: Did data collection and manuscript writing.SA: Takes the responsibility and is accountable for all aspects of the work in ensuring that questions related to the accuracy or integrity of any part of the work are appropriately investigated and resolved.

\section{Authors:}

1. Shahid Ahmed

Associate Professor, Department of Medicine,

2. Sajjad Jamil,

Consultant, Department of Gastroenterology,

Liaquat National Hospital \& Medical College, Karachi, Pakistan.

3. Hafeezullah Shaikh,

Assistant Professor, Department of Gastrenterology,

National Institute of Liver and GI Diseases,

Dow University of Health Sciences,

\& Consultant Zubaida Medical Center, Karachi, Pakistan.

4. Maryam Abbasi, Research Coordinator,

1,4: Darul Sehat Hospital, Karachi, Pakistan. 